\title{
Acute and chronic changes in massive barium sulfate aspiration in an infant who subsequently was diagnosed with severe gastro-esophageal reflux
}

\author{
Umit Gultekin', Sevgi Pekcan ${ }^{2 *}$ and Necdet Poyraz ${ }^{3}$ \\ *Correspondence: sevgipekcan@yahoo.com

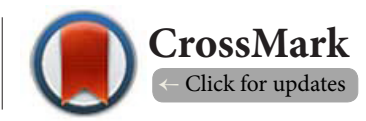 \\ 'Department of Pediatrics, Necmettin Erbakan University, Meram Medicine Faculty, Konya, Turkey. \\ ${ }^{2}$ Department of Pediatric Pulmonology, Necmettin Erbakan University, Meram Medicine Faculty, Konya, Turkey. \\ ${ }^{3}$ Department of Radiology, Necmettin Erbakan University, Meram Medicine Faculty, Konya, Turkey.
}

\begin{abstract}
The barium is often used in radiocontrast examinations of the digestive system because of mucosal absorption is limited. Massive barium aspiration is a rare complication, especially when there is no anatomic or neurological deficit. The depending on barium concentration can cause various lung effects. When the literature is reviewed, barium aspiration may be asymptomatic or lethal in massive amounts. Rarely, large amounts of barium sulphate are aspirated into the lung, there is no literature study how often this is happening. We present a case of massive barium aspiration in this subject. The case is related to a patient's diagnostic esophagography who complaints swallowing problems. The massive barium aspiration couldn't notice because of the absence of acute symptoms and surgical operation of gastrointestinal tract which the patient had undergone previously. When the patient applied our Pediatric Chest Diseases Polyclinic after three months, as a result of the examinations and deep research it was understood that the case was about massive barium aspiration. The patient was directed to our center because there was a radiological appearance of bone density signs on chest x-ray.Such a complaint was not reported by the family neighter in his biography, nor was written in the epicrisis. We will share acute and chronic changes in the lungs, diagnosis and treatment approaches of this case. The infant who has ileostomy was previously operated because of necrotizing enterocolitis. And also still has severe gastro-esophageal reflux and under conservative and medical treatment, a possible fundoplication surgery is planning.
\end{abstract}

Keywords: Barium aspiration, severe gastro-esophageal reflux, infant

\section{Introduction}

The barium often uses in radiological imaging of the gastrointestinal tract. Studies of the upper gastrointestinal system with barium, especially in patients with swallowing problems under risk of aspiration. The low quantities of barium aspirations encounter frequently and mostly asymptomatic but aspirations in massive quantities are rare and clinical studies are inadequate. Studies have shown that intensive barium aspiration may be fatal, especially in adults however it is quite clinical progress in infants. We present 4 months old infant who had massive barium aspiration during the pharyngoesophagography examination. That happened when she was 1 month old and applied to the Department of Pediatric Chest Diseases after 3 months. In our study, the relationship between barium aspiration in infancity and ratio of barium concentration, severe gastroesophageal reflux, prematurity. In addition that possible features of previous intestinal surgeon which could cover up the possible clinic nature of the barium aspiration.

\section{Case presentation}

A 4 months and 2435 gram infant, who had a history of 33 weeks premature birth and 1435 gram low birth weight, applied to our Child Chest Diseases Polyclinic. At the time of application; wheezing, coughing with sputum, vomiting and subfebril fever were present. Auscultation of her chest has not crackles and ronchi. There were decreased respiratory voices in the lung bases. There was no tachypnea, retractions or oxygen need. There was ileostomy in the abdomen after recurrent surgery- 
beceause of previous necrotizing enterocolitis. Blood gas and routine hemograms and biochemical values were normal in the laboratory tests. The infant was hospitalized, oral feeding was stopped and intravenous fluids infusion was started.

On the chest X-ray (Figure 1), hyperdense infiltrates were observed in both lungs which were more in the right middle and lower zone. Empiric antibiotherapy was started considering possible aspiration pneumonia. There was no septic situation in the patient. In her medical history that she had long-term hospitalizations in neonatal intensive care unit and used antibiotics during variable periods because of prematurity, low birth weight, gastrointestinal system pathologies. Although the infant was active, lively smiling and had a good overall condition. She had still swallowing problems and increased saliva secretion in the mouth. Nasogastric tube was performed and nutrition was followed. There was no desaturation or oxygen need.

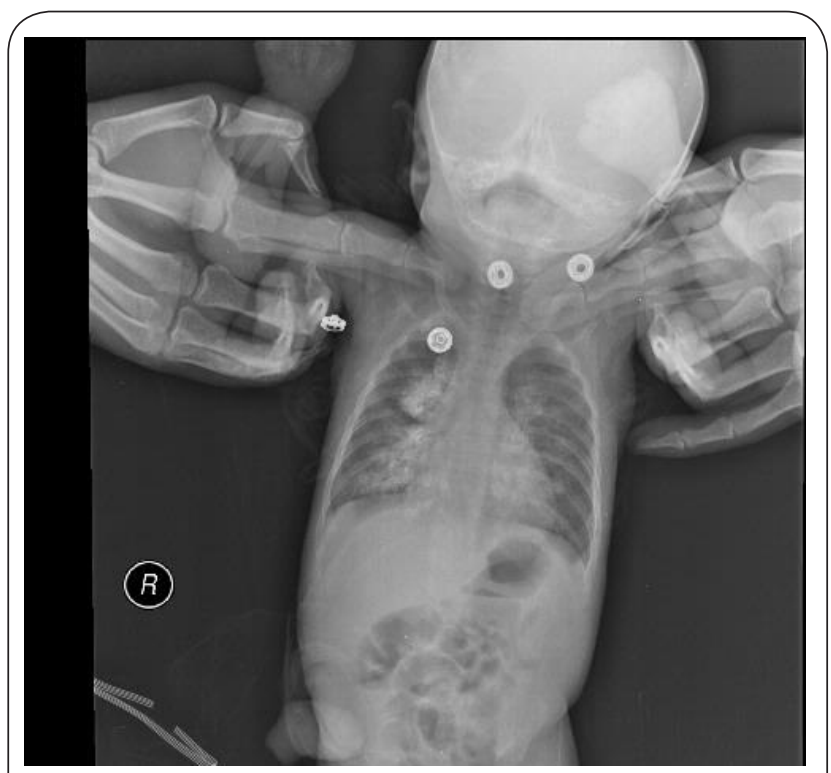

Figure 1. Application to the hospital, hyperdense areas especially in paracardiacareas.

Approximately three months ago when the infant was one month old that found out pharyngoesophageography with barium was taken at the external center due to swallowing problems and during the examination understood that the contrast matter extended to the trachea (Figure 2). It was learned that the patient who had been previously operated because of necrotizing enterocolitis. Before one week of the barium esophagografy that the patient reoperated in consequence of partial stenosis of the intestinal segments. It was thought that the subacute clinic which happened due to barium aspiration may be happened to hidden because of the recent gastrointestinal system surgery.

From medical history of the infant, it is learned that regur-

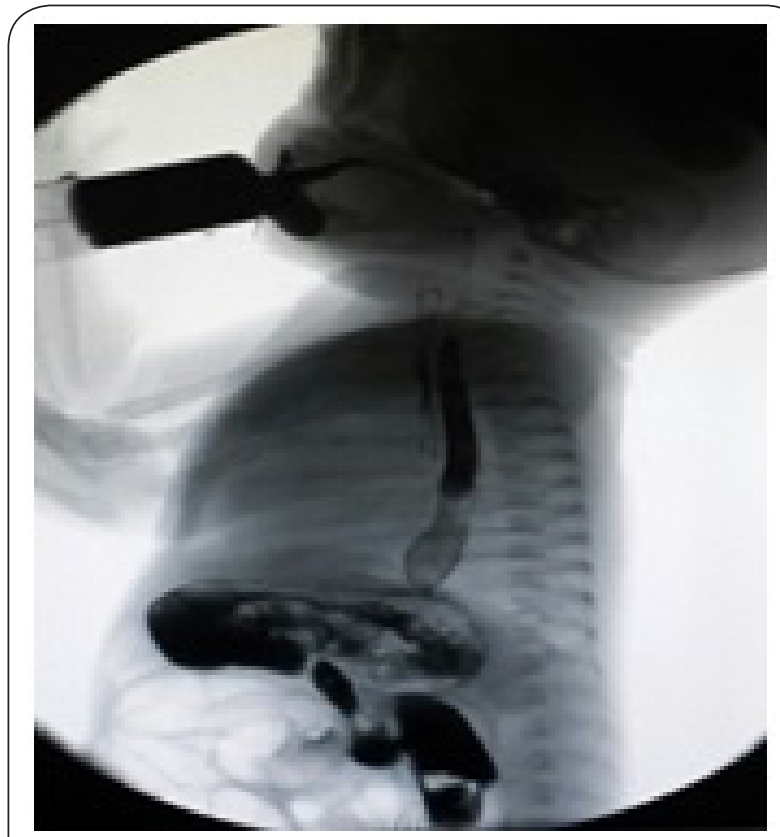

Figure 2. Esophagography.

During the examination, it is understood that the contrast medium extends to the trachea.

gitation had begun when she was three-days. She had been operated three times in totally and she can tolerated feeding without regurgitation after the ileostomy was opened in her third operation. On the day before barium radiography that auscultation findings were normal sPO2: 97 , respiratory rate: $44-56 / \mathrm{min}$, blood pressure $41 / 63$, heart rate: $138-160 /$ min. After barium radiography respiratory rate was 40-64/ $\mathrm{min}$, heart rate was $138-167 / \mathrm{min}$, bloodpressure was $40 / 59$. The following day respiratory rate was $48-82$ and abdominal distension, retraction, restlessness of the infant were present. It was thought that there was aspiration pneumania because of severe reflux. She was re-opated due to the abdominal distension. A few days later, a septic situation developed in infant and antibiotics were administered. She became desaturated without oxygen and was taken to nasal CPAP (Continuous Positive Airway Pressure) because of the tachypnea.Diuretic treatment was started to the infant who had hepatomegaly and considering heart failure. The patient was discharged from the hospital with good general condition after a month of follow-up and treatment.

The infant had re-applied to the external center one week later with increase of the sputum, saliva, cough and vomiting. The computed thoracic tomography showed that dense radioopacity especially in both lower lobes of the lungs. It was compatible with the barium contrast material aspirated in the pharyngoesophageal examination which was performed a month earlier (Figure 3). It was also observed that focal ground glass densities were present in the lower, middle lobe of the right lung, the lower lobe of the left lung which had depended 
to aspiration pneumonia by our colleagues. The chest X-ray had taken a few days after aspiration that had been similarly images (Figure 4).

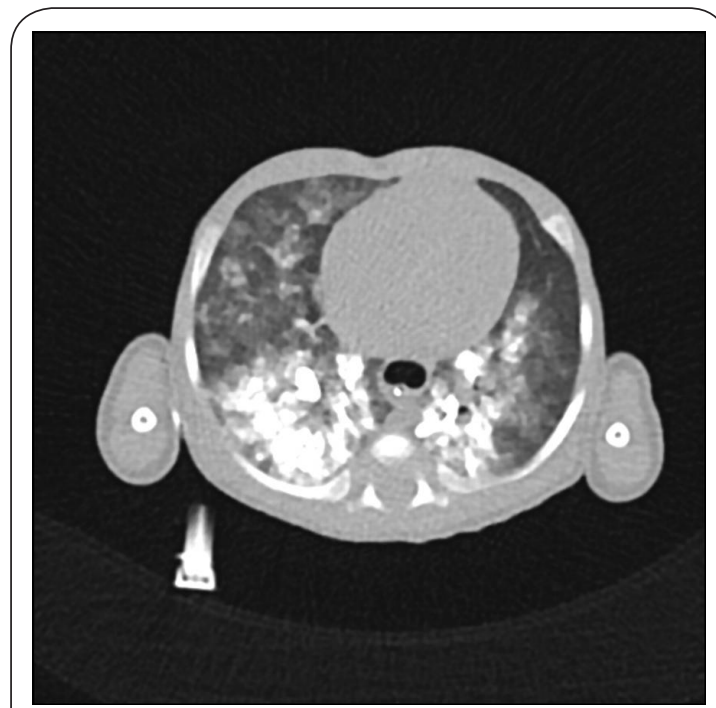

Figure 3. Unenhanced thoracic CT: diffuse patch opacity, particularly in the lower lobe posterior segments of both lung parenchyma. The lung parenchyma areas have ground glass densities.

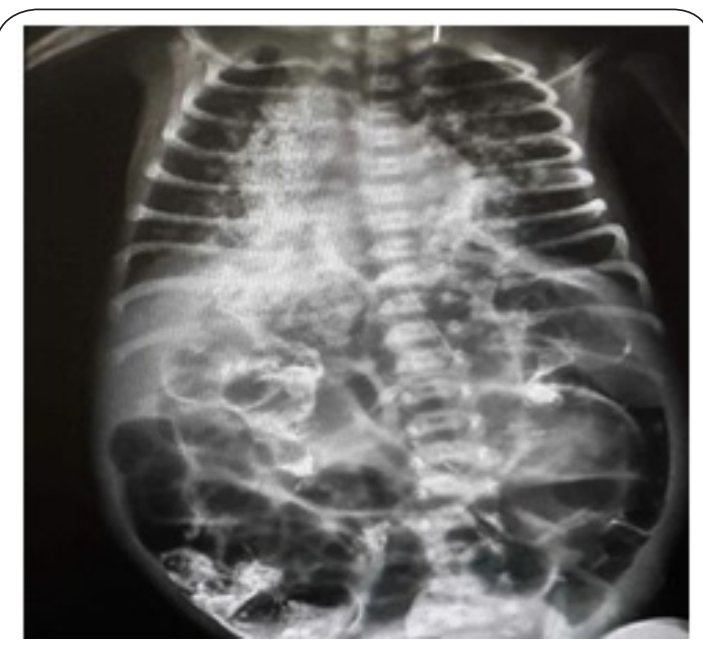

Figure 4. PA chest X-ray: right middle and lower zone marked, common hyperdense infiltrates in both lungs.

Flexible bronchoscopy was performed to exclude congenital structural abnormalities and remove any remaining quantities of the barium. Bronchoalveolar lavage was performed. There were no barium remains and lipid-laden macrophages in the submitted pathology material and also anatomic or structural pathology wasn't detected. There was a low weight gain of the infant with frequent regurgitations. The infant was continued feeding orally with small amounts at constantly intervals. The allergic tests were negative food panel and cow milk. Feeding with food concentrators were continued. Immunoglobulin levels, phagocyte system test and peripheral blood lymphocyte subgroups were normal. Several weeks of anti-acid therapy was started for the infant who continues to regurgitate. A 24-hour $\mathrm{pH}$ monitoring test was done after a few days break in treatment of the reflux and the index was above 10 (7 severe). The therapy is continued with proton pump inhibitors and prokinetics. After a while the patient admitted to our center several times because of recurrent pneumonias. Hyperdense areas due to barium on chest $\mathrm{X}$-ray were still peresent. Because of severe reflux can not be tolerated oral nutritions and oral medical treatment by the infant so possible surgical correction therapy is planned.

\section{Discussion}

Sucking in infants begin in uterus by suckling and swallowing of amniotic fluid. The tongue is characterized by a primitive movement from front to back. In premature infants disordered patterns of suckling with bursts and pauses can persist until 32th or 34th week of gestational age. After this time, sucking becomes more rhythmic and organized. The reflux can be more aggressive if the aspirated volume is too large [1]. Especially in the prematurity, it can be waited until a reasonable time passes before barium oral examinations.

latrogenic causes including the application of pharyngeal local anesthesia or the presence of orogastric or nasogastric tubes can prevent the swallowing function. If the child has a nasogastric tube, it is usually suggested to be left in its place.

Videofluoroscopic swallowing study or modified barium swallowing test is the initial procedure for evaluating pharyngeal and esophageal swallowing phases. In the examination, barium or other contrast material is used for the patient. Nasopharyngeal reflux, cricopharyngeal dysfunction and laryngeal penetration are commonly observed abnormalities. The presence of contrast material in the tracheobronchial tree is diagnostic for aspiration [2]. Low-osmolar iopamidol may be a possible alternative in children with a high risk of aspiration [3]. Barium swallowing examinations were made in Japan for the infants with recurrent pneumonia by using different concentrations of barium. While comparing the degree of aspiration and the barium concentration, it was found that the higher the concentration of barium is less severe the degree of aspiration [4]. In this study, barium was used in 10,30,60 w/v (weight/ volume) percentages. We used $100 \% \mathrm{w} / \mathrm{v}$ barium sulfate in our case. In this study in comparing the degree of aspiration and the barium concentration, it was found that the higher the concentration of barium, the less severe the degree of aspiration tended to be. But the result which was ${ }^{\prime} 10-20 \mathrm{w} / \mathrm{v} \%$ barium should be used in barium swallow examinations for infants with recurrent pneumonia' seems to be contradictory.

Aspiration of large amount of low-density barium sulfate $(100 \%, \mathrm{w} / \mathrm{v})($ comparing with $160 \% \mathrm{w} / \mathrm{v})$ is potentially 
life-threatening because of mechanical interference to gas exchange, accumulation of barium sulfate within alveolar spaces causes alveolar shunting and this ventilation leads to perfusion (V/Q) abnormalities [5]. The clinical findings of our case in the first few days which were accepted and treated as sepsis may depend on those distribution abnormalities.

Kineztherapy along with postural drainage that bronchoscopy for removal of contrast material, prophylactic antibiotic therapy are currently recommended [3]. In our case, antibiotics were started in the early period considering sepsis. The patient applied to our center three months after the barium aspiration; therefore bronchoscopy was done in consideration of possible benefits in the late period. After the oral barium graphies the possibility of aspiration should keep in mind and bronchoscopy should be done as soon as possible to minimize the possibility of the fibrosis which can develop in the future in the lungs.

In a study which was done about value of change in the posture in order to prevent barium aspiration during video fluoroscopic swallowing studies. It was proved that changes in head or body position eliminated aspiration of at least one of the swallowings in $77 \%$ of the patients. When four extra swallowings were analyzed, $25 \%$ of the patients did not have aspiration, either. Postural techniques can eliminate aspiration of barium in most patients and they should be advice to barium oropharyngeal studies [6].

Following a contrast study, Lopez-Castilla and his colleagues described a 2-month-old child with gastro-esophageal reflux who developed acute respiratory distress and oxygen need after barium aspiration [7]. In our case, the high index reflux which was obtained after 24 hour $\mathrm{pH}$ monitoring indicates that this is one of the main reasons of the aspiration. In a study on healthy infants who are 13 months old and younger regurgitation was reported at least once a day for about half of the infants aged 0-3 month-old when compared to infants aged 10-12 months. This symptom decreased to $5 \%$ for 10 to 12 months of age $(P<0.001)$. Peak reported regurgitation was $67 \%$ at 4 months; the prevalence of symptoms decreased dramatically from $61 \%$ to $21 \%$ between 6 and 7 months of age [8]. Barium aspiration occurred in our case when she was one month old. The test was performed during this period (0-3 month) that made us to think that the risk is likely to increase.

In a study describing the long-term effects of barium aspiration through a literature review and a case report [9] variety of information is provided. Small amounts of barium are usually well-tolerated in the bronchial tree. After aspirated once, the barium particles that are not coughed out or removed by mucociliary clearance accumulate in alveolar spaces [10].

Voloudaki et al., Used high-resolution CT scans, concluded that the barium particles are likely to be phagocytosed by alveolar macrophages and can potentially cause interstitial fibrosis by crossing into the alveolar or peribronchial interstitial tissue [11]. These authors reported thickening of interlobular septae, the presence of sub-pleural cysts and centrilobular micronodules containing barium particles with sub-pleural distributionin adults 1 year after barium inhalation. They stated that barium is capable of producing clinically mild, silent fibrosis. Venkatraman et al., reported peribronchial interstitial changes after barium aspiration [12]. In contrast, Marchiori et al., described baritosis in which inhaled particulate matter lies in the lungs for years without producing symptoms and that interfere with lung function and is responsible for the development of pulmonary or bronchial infections or other thoracic disease [13]. Before starting high-resolution CT scans for the diagnosis of bronchiectasis, barium and even oil contrast bronchograms were frequently performed. Nelson et al., reported in an invaluable study in which 89 patients underwent barium sulfate bronchography at intervals up to 6 months before lung resection [14]. There was no evidence of histologic fibrotic pulmonary changes until up to 6 months after the bronchograms [9].

\section{Conclusion}

Especially in a case of prematurity, if barium oral examination is going to be performed, it could be waited until 34th week of the gestasional age when the development of the suction reflex is completed. Especially in young infants, contrasting substances which can also be used intravenously may be preferred first. If barium is to be preferred, guidelines for concentration and delivery postures should be developed and must be provided by application units. If gastroesophageal reflux is suspected, pH monitoring should be performed before contrast-enhanced examination. The possibility of aspiration should not be missed after barium trials and bronchoscopy for bronchoalveolar lavage should be planned as soon as possible.

\section{Competing interests}

The authors declare that they have no competing interests.

Authors' contributions

\begin{tabular}{|l|c|c|c|}
\hline Authors' contributions & UG & SP & NP \\
\hline Research concept and design & $\checkmark$ & $\checkmark$ & -- \\
\hline Collection and/or assembly of data & $\checkmark$ & $\checkmark$ & -- \\
\hline Data analysis and interpretation & $\checkmark$ & -- & -- \\
\hline Writing the article & $\checkmark$ & -- & -- \\
\hline Critical revision of the article & $\checkmark$ & $\checkmark$ & $\checkmark$ \\
\hline Final approval of article & $\checkmark$ & $\checkmark$ & $\checkmark$ \\
\hline Statistical analysis & $\checkmark$ & -- & -- \\
\hline
\end{tabular}

\section{Publication history}

Senior Editor: Basil O. Ibe, Harbor-UCLA Medical Center, USA. Received: 21-May-2017 Final Revised: 25-Jun-2017

Accepted: 26-Jul-2017 Published: 09-Aug-2017

\section{References}

1. Kakodkar K and Schroeder JW, Jr. Pediatric dysphagia. Pediatr Clin North Am. 2013; 60:969-77. I Article I PubMed

2. Darrow DH and Harley CM. Evaluation of swallowing disorders in children. Otolaryngol Clin North Am. 1998; 31:405-18. I PubMed

3. Morton RE, Bonas R, Fourie B and Minford J. Videofluoroscopy in the 
Gultekin et al. Pulmonology and Respiratory Research 2017,

http://www.hoajonline.com/journals/pdf/2053-6739-5-2.pdf

assessment of feeding disorders of children with neurological problems. Dev Med Child Neurol. 1993; 35:388-95. | Article | PubMed

4. Hiorns MP and Ryan MM. Current practice in paediatric videofluoroscopy. Pediatr Radiol. 2006; 36:911-9. | Article | PubMed

5. Tamm I and Kortsik C. Severe barium sulfate aspirationinto the lung: clinical presentation, prognosis and therapy. Respiration. 1999; 66:81-4. I PubMed

6. Gray C, Sivaloganathan S and Simpkins KC. Aspiration of high-density barium contrast medium causing acute pulmonary inflammation-report of two fatal cases in elderly women with disordered swallowing. Clin Radiol. 1989; 40:397-400. | Article | PubMed

7. Nishikawa MA. Study of aspiration in infants with recurrent pneumonia by Barium swallow examination using different concentrations of barium Nihon IgakuHoshasen Gakkai Zasshi. 1994; 54:129-36.

8. Chiu CY, Wong KS and Tsai MH. Massive aspiration of barium sulfate during an upper gastrointestinal examination in a child with dysphagia. Int J Pediatr Otorhinolaryngol. 2005; 69:541-4. | Article | PubMed

9. Rasley A, Logemann JA, Kahrilas PJ, Rademaker AW, Pauloski BR and Dodds WJ. Prevention of barium aspiration during videofluoroscopic swallowing studies: value of change in posture. AJR Am J Roentgenol. 1993; 160:1005-9. | Article | PubMed

10. Lopez-Castilla JD, Cano M, Munoz M, Soult JA, Andres A, Montilla M and Barrera M. Massive bronchoalveolar aspiration of barium sulfate during a radiologic study of the upper digestive tract. Pediatr Pulmonol. 1997; 24:126-7. | PubMed

11. Nelson SP, Chen EH, Syniar GM and Christoffel KK. Prevalence of symptoms of gastroesophageal reflux during infancy. A pediatric practice-based survey. Pediatric Practice Research Group. Arch Pediatr Adolesc Med. 1997; 151:569-72. | Article | PubMed

12. Jackson M, Kapur N, Goyal V, Choo K, Sarikwal A, Masters IB and Isles AF. Barium aspiration in an infant: a case report and review of management. Front Pediatr. 2014; 2:37. | Article | PubMed Abstract | PubMed FullText

13. Roggli V and Shelburne J. Mineral pneumoconiosis. 2nd ed In: Dahl DH, Hammar SP, editors. editors.Pulmonary Pathology. New York: SpringerVerlag. 1998; 589-618.

14. Voloudaki A, Ergazakis N and Gourtsoyiannis N. Late changes in barium sulfate aspiration: HRCT features. Eur Radiol. 2003; 13:2226-9. | Article I PubMed

15. Venkatraman B, Rehman HA and Abdul-Wahab A. High resolution computed tomography appearances of late sequelae of barium aspiration in an asymptomatic young child. Saudi Med J. 2005; 26:665-7. I PubMed

16. Marchiori E, Souza AS, Jr., Franquet T and Muller NL. Diffuse highattenuation pulmonary abnormalities: a pattern-oriented diagnostic approach on high-resolution CT. AJR Am J Roentgenol. 2005; 184:273-82. | Article | PubMed

17. Nelson SW, Christoforidis A and Pratt PC. Barium sulfate and bismuth subcarbonate suspensions as bronchographic contrast media. Radiology. 1959; 72:829-38. | Article | PubMed

\section{Citation:}

Gultekin U, Pekcan S and Poyraz N. Acute and chronic changes in massive barium sulfate aspiration in an infant who subsequently was diagnosed with severe gastro-esophageal reflux. Pulmonol Respir Res. 2017; 5:2. http://dx.doi.org/10.7243/2053-6739-5-2 